\title{
O Mestrado em Ensino da História na Universidade do Minho (Portugal): o testemunho de um (ex-)aluno
}

Master degree in History teaching at the University of Minho, Portugal: An (ex-)student's testimony

Hugo Ferreira Cardoso

\section{RESUmo}

O artigo apresenta uma reflexão crítica sobre o modelo de formação de professores em mestrado profissionalizante para o ensino de História e Geografia para o $3^{\circ}$ ciclo do Ensino Básico e o Ensino Secundário (2009-2014) sob a perspetiva de um formando. Apesar de esse curso ter um formato bidisciplinar, focamos apenas a área adstrita ao ensino da História. Foi eleito como primeiro tema a estrutura curricular do curso, na sua área da especialidade (História) e na área científica (Ciências da Educação), que defende um perfil de professor como um prático reflexivo e crítico. Assim, dá-se relevo à investigação pedagógica no estágio através da construção e avaliação de um "projeto de intervenção pedagógica supervisionada” (PIPS). Palavras-chave: formação de professores; História; investigação, prática pedagógica.

\section{Abstract}

The article presents a critical reflection, from a learner' perspective, on the teachers' training model that the Master degree in History and Geography teaching ( $3^{\text {rd }}$ cycle of Basic Education and Secondary education) provided by the university of Minho, Portugal (20092014). Although is a bidisciplinar degree we will focus aspects concerning the teaching of history. Firstly, we reflect on the curricular structure of the course that covers two areas: History and in Science Education, that supports a teacher' profile as a reflexive and critical practitioner. Therefore, we underline the relevant place given in this degree to pedagogical research developed during the training practice substantiated on the construction and implementation of a 'supervised teaching intervention project' (PIPS).

Keywords: teacher education; History; research, professional practice.

\footnotetext{
* Mestre em Ensino de História, Universidade do Minho, Braga, Portugal. cardoso.hugo@gmail. com
} 
O presente texto pretende refletir sobre o modelo de formação de professores no ensino de História e Geografia no $3^{\circ}$ ciclo do Ensino Básico e no Ensino Secundário ${ }^{1}$ que é oferecido na Universidade do Minho na perspetiva de um ex-formando (2009-2014). Esta reflexão assenta, sobretudo, na minha experiência enquanto aluno no mestrado e estagiário de História no Ensino Secundário.

O contexto de formação e a caraterização do ciclo de estudos do mestrado encontram-se explanados no artigo de Maria do Céu de Melo inserido neste dossiê. Desse modo, a montante será eleito como primeiro tema uma reflexão crítica sobre a estrutura curricular do curso, na sua área da especialidade (História) e na área científica (Ciências da Educação), e a jusante, a criação e a implementação do Projeto de Intervenção Pedagógico Supervisionado (PIPS) inserido na experiência pedagógica do estágio profissional. É de relembrar que como testemunho, o registo deste texto é pessoal, assumindo uma postura crítica que a distância e o tempo entre a vivência e a escrita permitem.

\section{A ESTRUTURA CURRICULAR Do CURSO}

$\mathrm{Na}$ Universidade do Minho, o Mestrado em Ensino de História e Geografia no $3^{\circ}$ ciclo do Ensino Básico e no Ensino Secundário surge na sequência de um primeiro ciclo de estudos no qual se realiza uma licenciatura em História ou Geografia, apresentando-se um conjunto de opções para prosseguir para o $2^{\circ}$ ciclo de estudos. Neste último ciclo, os mestrados profissionalizantes assestam para a habilitação profissional para a docência.

No primeiro ano do plano curricular do mestrado, as didáticas específicas têm lugar central, cuja componente formativa é constituída por 280 horas, onde assumem um caráter amplamente prático com foco na utilização de uma metodologia investigativa. Todavia, a bifurcação das didáticas específicas em História e em Geografia exigiu a repartição das cargas horárias, resultando numa amputação do tempo que se deveria dedicar à análise de situações educativas e à mobilização dos conhecimentos científicos para uma abordagem educativa em contextos de sala de aula. Em outro sentido, as disciplinas de componente educacional na área das Ciências da Educação foram depuradas e apresentam um vasto leque de formação, nomeadamente, na Sociologia da Educação e Profissão Docente, Desenvolvimento Curricular, Correntes 
Fundamentais da Pedagogia, Psicologia da Motivação e da Aprendizagem, Ética e Deontologia da Prática Docente, Psicologia da Adolescência e Organização da Escola. As disciplinas revestem-se de um carácter predominantemente teórico, que procuram fundamentar devidamente a prática educativa através de referências e instrumentos essenciais para a apreensão da complexidade das situações educativas. O plano de estudos introduziu a disciplina de Tecnologia Educativa para produzir, do ponto de vista pedagógico, materiais educativos mediatizados e otimizar, na sala de aula, a relação entre professor e aluno.

O segundo ano consiste numa imersão em meio escolar mediante estágio, em contexto profissional, nas disciplinas de especialidade, acompanhado por um orientador na escola e sob a supervisão de um docente na universidade. $\mathrm{O}$ estágio pedagógico é concretizado por meio de

atividades diferenciadas que incluem a observação, a análise e a responsabilização por atividades docentes. Estas atividades dirigem-se ao desenvolvimento da competência docente, entendida esta não como um conjunto de micro-competências adicionais, mas como uma realidade holística, onde se valorizam conhecimentos, capacidades, atitudes, níveis de adequação de intenções, todos expressos num conjunto de relações interpessoais e institucionais, que determinam o exercício competente da profissão. (CRUP, 2001, apud Guimarães, 2006, p.280)

Esse percurso de iniciação à prática profissional foi concebido para promover uma "postura crítica e reflexiva em relação aos desafios, processos e desempenhos do quotidiano profissional" (Vieira et al., 2013, p.2462). A definição desse perfil enquadra-se no Decreto-Lei no 43/2007, que valoriza a "fundamentação da prática de ensino na investigação” (ibidem) e sublinha

a necessidade que o desempenho dos educadores e professores seja cada vez menos o de um mero funcionário ou técnico e cada vez mais o de um profissional capaz de se adaptar às características e desafios das situações singulares em função das especificidades dos alunos e dos contextos escolares e sociais. (p.2462)

Concomitantemente, a estrutura curricular do mestrado enquadra-se no Perfil Geral de Desempenho Profissional do Educador de Infância e dos professores do Ensino Básico e Secundário (Decreto-Lei no 240, de 30 ago. 2001), mas também ao integrar de forma transversal aspetos de componente de 
Formação Cultural, Social e Ética subjacentes na estrutura curricular, que se tornam referenciais que pautam a prática pedagógica inerentes a um desempenho docente adequado e responsável. É de referir que o Decreto-Lei citado define um perfil geral de professor tendo em conta: 1. A dimensão de desenvolvimento do ensino e da aprendizagem que foca aprendizagens no quadro de uma relação pedagógica de qualidade, integrando critérios de rigor científico, metodológico e pedagógico, ${ }^{2}$. A dimensão de participação na escola e de relação com a comunidade indica o tipo de papel que o professor deve desempenhar na escola, com os alunos e com a comunidade escolar; ${ }^{3}$. A dimensão do desenvolvimento profissional ao longo da vida remete para a reflexão das suas práticas, no desenvolvimento de competências pessoais, sociais e profissionais, numa perspetiva de formação ao longo da vida, e participa em projetos de investigação relacionados com o ensino, a aprendizagem e o desenvolvimento dos alunos.

\section{A DIDÁTICA DA HisTóRIA}

Neste mestrado profissional, a área da especialidade denominada de Didática (da História e da Geografia) encontra-se disseminada nos seus 2 anos nas seguintes unidades curriculares (UC): Metodologia do Ensino da História e Avaliação e Conceção de Materiais Didáticos de História (ver Zeichner, 2010). Elas afiguram-se como bastante relevantes no quadro de uma formação em ensino da História e têm sido continuamente redefinidas em função das reestruturações do curso e dos planos de estudo do ensino da disciplina de História no sistema educativo português, e de acordo com os contributos que a investigação em Educação Histórica feita em Portugal e no estrangeiro tem trazido para o seu exercício em contextos escolares e outros contextos educativos.

É clara uma atribuição de relevância dada a essa sustentação teórica e empírica como sustentação não apenas das orientações para nós, futuros professores, sobre as práticas e discursos pedagógicos a implementar no quotidiano escolar, como também para os processos de construção da História pelos alunos inscritos nos diferentes graus de ensino. Daí uma presença curricular forte no plano do curso de mestrado da UC adstrita à Metodologia de Ensino e Avaliação e Conceção de Materiais. É de destacar também dois princípios 
pedagógicos que são a espinha dorsal das práticas dos professores e alunos nestas UCs: a da reflexividade e autonomia. Eles não se apresentam apenas como uma pauta substantiva e procedimental entre alunos e professores universitários, mas também como princípios orientadores da construção e implementação do processo de ensino-aprendizagem da disciplina de História nas escolas, nossos futuros locais de trabalhos (Melo, 2004).

No primeiro semestre ( $1^{\circ}$ ano) apresenta-se a UC de Metodologia do Ensino da História, que assenta em conteúdos introdutórios que visam uma progressiva tomada de consciência da futura condição de professores, mobilizando e reequacionando os conhecimentos científicos históricos para uma abordagem educativa e uma reflexão sobre os desafios e propostas educativas atuais, bem como, o papel da História no currículo. Ela organiza-se em três partes, nomeadamente: 1 . Os contributos da investigação em educação histórica como referentes de novas práticas de ensino e aprendizagem; 2. A investigação-ação como estratégia de desenvolvimento profissional e geradora de implementações de novas práticas de ensino e de aprendizagem; 3. A sala de aula de História - práticas e discursos: Ideias tácitas, conhecimento substantivo, e de segunda ordem em História; Orientaçoes curriculares de História nos ensinos Básico e Secundário; Práticas de ensino e aprendizagem de História em contextos formais e não formais. Esta UC apresenta uma forte relevância para a formação uma vez que se centra na aquisição de competências de compreensão do quadro teórico e de utilização de uma metodologia investigativa relativa ao Ensino da História, mas também, na mobilização de conceitos e de perspetivas atuais no âmbito do ensino e aprendizagem da História. As estratégias de formação privilegiaram, principalmente, a análise e a discussão de estudos de investigação em Educação Histórica e textos orientadores, problematizando a sua aplicação prática, a fundamentação de várias metodologias e estratégias de aprendizagem e elaboração de pequenos projetos realizados em grupo sobre temas trabalhados na sala de aula (por exemplo: ideias tácitas, narrativas dos alunos, leitura de diferentes tipos de fontes históricas etc.). A construção e a implementação destes últimos permitiram colocarmo-nos em situações de partilha de responsabilidades, de experiências e de troca de conhecimentos, o que podendo parecer banal, é por vezes não apenas inovadora como desafiadora face às práticas que atribuem aos alunos universitários um papel frequentemente passivo. Com efeito, com a adoção destas metodologias 
pretende-se contribuir para uma vertente do perfil do professor de História que é o de investigador, já que neste mestrado se advogou um profissional que se questiona, que tenta compreender o modo como os alunos aprendem, e que tenta fazer opções metodológicas sustentadas. A avaliação dessa UC foi feita mediante um teste/reflexão individual2 e um portfólio de grupo que explicitasse não apenas os trabalhos realizados, mas também uma reflexão escrita. A implementação destas atividades e deste tipo de avaliação permitiu satisfatoriamente revelar uma reflexão pessoal contemplando os vários momentos processuais da aprendizagem realizados ao longo da UC. Ressalvamos, igualmente, a reflexão feita sobre práticas em Educação Histórica no âmbito das preocupações de uma Educação para a Cidadania. Resumindo, cremos que foram desenvolvidas competências inerentes a um pensamento crítico, que nos permitiu desenvolver uma crescente consciência sobre as escolhas que teríamos de fazer sobre qual tipo de aprendizagem histórica iríamos adotar no ano seguinte (estágio profissional). Esta UC exigiu particularmente o exercício de uma reflexão crítica que desconstruísse alguns quadros teóricos e práticos aprendidos no grau de ensino anterior (Licenciatura em História), como a análise crítica dos estudos que nos eram apresentados como modelos ou pelo menos inspiradores para o futuro profissional (Melo, 2004).

No terceiro semestre ( $2^{\circ}$ ano) apresenta-se a UC de Avaliação e Conceção de Materiais Didáticos de História e de Geografia que se desdobra, assim, em duas especialidades partilhando, consequentemente, a disponibilidade total de 280 horas. Trata-se de uma disciplina bicéfala que assenta em conteúdos de aprofundamento que visam a mobilização de conhecimentos adequados à investigação em ensino e aprendizagem da História e Geografia, e na avaliação e conceção de materiais didáticos. Como explícito, apresenta um forte teor prático onde são elaborados projetos de prática pedagógica e atividades de simulação de ensino e aprendizagem (planos de aulas; pequenos projetos, visitas de estudo etc.). Mediante estas caraterísticas formativas e metodológicas, o número total de horas disponibilizadas revelou-se insuficiente, criando limitações no que concerne ao aprofundamento das duas especialidades. Não obstante, foi possível desenharem-se situações de ensino e aprendizagem à luz das conceções do construtivismo, afiguraram-se metodologias, instrumentos, conhecimentos e conceções de materiais pedagógicos assaz distintos. A UC (ver Guimarães, 2006) organizou-se em quatro temas: 1. Paradigmas no Ensino da História na conceção 
e avaliação de materiais didáticos; 2 . Desenho de trajetos didáticos: da aula expositiva à aula-oficina; 3 . Conceção de tarefas de aprendizagem: definição, construção e avaliação; ${ }^{4}$. As metodologias histórico-geográficas aplicadas à perceção e valorização do(s) Património(s). Ela procurou desenvolver nos alunos, num quadro de reflexividade, atitudes de reflexão pessoal no decurso do processo de aprendizagem. As atividades obedeceram a uma participação individual e a uma prática colaborativa, em que se privilegiou a elaboração de trabalhos de grupo para a construção de um dossiê constituído por materiais pedagógicos produzidos e em reflexões individuais de nível metacognitivo. Uma vez mais, as estratégias de formação privilegiaram a integração dos contributos da investigação em Educação Histórica para a conceção e avaliação de materiais didáticos e a sua aplicabilidade em situações simuladas de ensino e aprendizagem. Consideramos que a implementação destas atividades resultou no desenvolvimento de processos de autonomia e de cariz investigativo que permitiu colocar os alunos numa situação de partilha de responsabilidades e de divulgação de interações e de conhecimentos para fundamentar a prática pedagógica. É de notar que esta UC é realizada antes do Estágio profissional (4º semestre). Sintetizando, as UCs alocadas na área científica da Didática foram cuidadosamente organizadas e planificadas com conteúdos e práticas autónomos e investigativos relevantes, os quais proporcionaram a formação do professor como um prático reflexivo e crítico. Estes saberes foram fundamentais para o desafio que foi o novo contexto de formação - o estágio pedagógico, onde se conferiu, como veremos em seguida, um lugar de relevo à prática pedagógica (propriamente dita) e à investigação pedagógica.

\section{O Estágio Pedagógico}

O estágio pedagógico, ou a UC de Estágio Profissional, de acordo com o modelo específico de formação na Universidade do Minho, é realizado em escolas do Ensino Básico e do Ensino Secundário, com a duração de 1.260 horas, e materializa-se no $2^{\circ}$ ano do Mestrado. O terceiro semestre foi composto por três módulos:

a) A prática de observação de situações educativas consistiu em visitas às escolas onde iríamos realizar o nosso estágio (no meu caso, uma escola 
secundária) onde fomos integrados através das orientadoras-cooperantes (professoras responsáveis pelas turmas) na dinâmica da escola e nas turmas onde iriamos lecionar. Esta prática de integração foi também usada como um momento de observação de aulas das orientadoras, prática que foi precedida de uma fase de preparação, apoiada numa reflexão sobre a especificidade das turmas, das aulas na área das ciências sociais, e na análise de textos orientadores. Foi sendo produzido um diário descritivo e reflexivo, tendo em conta as variáveis de ensino e de aprendizagem assim como aspetos diferenciados que corresponderam a questionamentos do contexto educativo onde seria implementado o Projeto de Intervenção Pedagógica Supervisionada (PIPS);

b) Um segundo módulo consistiu no desenho do PIPS sustentado pela recolha de dados oriundos da observação do contexto escolar e das turmas. Ele iniciou-se ainda no $3^{\circ}$ semestre e continuou pelo seguinte, traduzindo primeiramente, na elaboração de planos de aula, a produção de material pedagógico e a conceção do projeto de intervenção;

c) O terceiro módulo substanciou-se na 'real' lecionação das aulas que me tinham sido destinadas (turma, ano de escolaridade e conteúdos programáticos) onde foi implementado o PIPS. Todas estas ações foram permanentemente acompanhadas pelo supervisor da universidade que apreciou as propostas, as fundamentações e as estratégias pedagógicas em parceria com as orientadoras cooperantes. O PIPS é um pequeno projeto de investigação (estudo de caso) que é implementado na dinâmica natural da nossa prática profissional, fazendo assim parte da planificação do conjunto de aulas que nós tínhamos de lecionar segundo o regulamento de estágio.

De forma sintética, poderei caracterizar que neste $2^{\circ}$ ano do Mestrado fomos envolvidos simultaneamente em aprendizagens e procedimentos de metodologias de ensino de cariz construtivista, exigindo a construção de um projeto pedagógico (a montante), e numa iniciação à prática de investigação (a jusante). Com efeito, foi possível vivenciar um perfil de estágio pedagógico que se enformou por pressupostos e princípios de orientação reflexiva, e onde se almeja uma articulação estreita entre a prática pedagógica e a prática investigativa. Este modelo de estágio pretendeu conferir assim à prática pedagógica 
uma natureza transformadora e emancipatória (Zeichner, 2010; Vieira et al., 2013), e criar mesmo que ainda de forma iniciatória um "terceiro espaço" de natureza multidisciplinar e teórico-prática, onde os futuros professores devem educar investigando e investigar educando, e onde a ação educativa envolve a confluência de saberes disciplinares e educacionais, experienciais e teóricos, substantivos e processuais.

Apresentados mesmo que de modo breve, o modelo e o contexto do estágio pedagógico têm alguns aspetos que considero relevantes e que podem ser lidos como um produto reflexivo da minha experiência pedagógica do estágio profissional.

Primeiramente, é de focar os constrangimentos identificados na estrutura curricular do estágio. Assim, observaram-se problemas que denunciam uma desconexão temporal na unidade curricular Estágio Profissional oriunda da exigência de cumprimento de tarefas num calendário restrito, por vezes impossíveis de serem realizadas, ou pelo menos, frutiferamente realizadas: 1) A frequência presencial na Universidade de Minho de unidades curriculares3 (submódulos e UCs optativas) e as atividades de observação das aulas em contexto real das aprendizagens que exigiam não apenas viagens como o respeito pelos horários e as disponibilidades das orientadoras cooperantes das escolas; 2) A existência de diferentes momentos e formatos de avaliação dos referidos submódulos (testes, ensaios, projetos etc.) que criaram frequentemente uma dispersão das tarefas mais relevantes que eram a preparação e o exercício da prática pedagógica, e a criação e implementação do PIPS.

Segundamente, a integração almejada do PIPS na dinâmica natural da prática pedagógica trouxe para alguns de nós problemas, gerados por problemas diversos, dos quais daremos apenas dois exemplos: a pressão escolar por cumprir os conteúdos programáticos não se compadecia com a prática de implementação de instrumentos de recolha de dados dos PIPS que exigiam um tempo de trabalho superior ao tempo dado para cada aula (90'); os tempos atribuídos 'legalmente' para a lecionação de certos conteúdos não eram compatíveis com uma prática investigativa (e de aprendizagem) adequada (por exemplo: construção de gráficos pelos alunos) (Cardoso, 2013). É de esclarecer que a distribuição do número de aulas para cada tema é acordada no início de cada ano escolar no seio do grupo de todos os professores de História (o mesmo para todas as disciplinas escolares). A pressão é feita entre colegas, pelos 
outros órgãos das escolas e pelos pais. Nos anos em que há exames nacionais essa pressão é também assumida pelos próprios alunos. Essa situação tem vindo a ser agudizada pelas últimas reformas educativas perpetradas pelo Ministério da Educação e Ciência (MEC) (2011), dentre elas a de realçar a diminuição de número de horas semanais para as disciplinas de História e Geografia e a diminuição de oferta dessas disciplinas nos cursos do ensino secundário.

Um terceiro problema intimamente relacionado com o anterior atém-se com o reduzido número de horas efetivas de lecionação atribuído a cada estagiário numa só turma,4 o que 'obrigou' a que a implementação do PIPS não fosse feita dentro da planificação da prática pedagógica, mas em espaços-tempos acordados com os alunos e orientadores cooperantes. ${ }^{5}$ Esse constrangimento resultou frequentemente da dificuldade da Universidade em encontrar professoras que se dispusessem a cooperar apesar da existência de protocolos.

Um quarto aspeto que considero importante salientar diz respeito à natureza bidisciplinar do mestrado (ver nota 1). Neste, ao professor estagiário exige-se o domínio do conteúdo científico, humanístico, tecnológico ou artístico de ambas as disciplinas, bem como integrar esses conhecimentos em contexto de sala de aula. Todavia, não se sentiu no plano de estudos do mestrado a promoção de projetos de interdisciplinaridade com a inclusão de projetos que entrecruzassem a História e a Geografia, tendo para tal que as UCs da área da didática (ou algumas das suas sessões) fossem lecionadas pelos dois professores.

Por último, subsistiram para nós desafios referentes ao seu duplo estatuto (Guimarães, 2006; Formosinho, 2009), simultaneamente alunos universitários e futuros professores, o que constitui um problema complexo já que são múltiplas as expectativas quanto aos comportamentos, funções e obrigações dos dois papéis. Essa ambiguidade foi sentida em momentos nos quais o nosso envolvimento ou até apenas a presença física era igualmente requestada pela Universidade e pelas escolas cooperantes. Como recomendação creio que deve haver uma reestruturação dos módulos e submódulos que compõem a unidade curricular do Estágio Curricular, numa conceção isomórfica de proporções modulares que articulem com coerência o processo formativo. Considero também que deve ser dada maior autonomia e tempo de lecionação aos estagiários para implementação do projeto e criação, com os alunos, de uma maior 
dinâmica no processo de ensino-aprendizagem que só pode ser gerada a partir de uma relação professor-aluno feita com tempo. Deve ser igualmente reforçada a cooperação institucional entre as Escolas e as Universidades que oriente e organize uma melhor integração dos professores estagiários. Por último, o mestrado deve focar-se num modelo que privilegie uma única disciplina de especialidade para que a formação investida pelos alunos mobilize uma consciencialização do conhecimento científico e disciplinar e reforce a eficácia da formação e das práticas pedagógicas (ver nota 1).

Por fim, é minha vontade sublinhar a experiência pedagógica vivida na lecionação das aulas. Esta foi extremamente positiva, tendo estabelecido, desde o primeiro momento, uma excelente relação com os alunos. É importante um professor deixar transparecer aos alunos a motivação e o gosto pessoal pelos conteúdos lecionados. Consciente dessa premissa, encontrei fôlego para a prossecução deste projeto na excelente atitude e motivação dos alunos, deixando-me envolver por um sentimento de entrega, cooperação e participação ativa de todos os elementos envolvidos nas atividades propostas ao longo das minhas aulas. Não obstante os resultados obtidos, considero que o caminho a percorrer ainda agora se terá iniciado, e que estudos e ações futuros devem ter em vista implementação de estratégias diferenciadas dentro da sala de aula, esboçando novos objetivos, novos métodos de ensino, numa constante procura da potenciação plena dos recursos humanos e materiais disponíveis.

\section{REFERÊNCIAS}

CARDOSO, Hugo. A apreciação estética na História da Cultura e das Artes e a construção de gráficos na Geografia: um estudo com alunos do ensino secundário. Tese (Mestrado em Ensino de História e de Geografia no $3^{\circ}$ Ciclo do Ensino Básico e no Ensino Secundário). Instituto da Educação, Universidade do Minho. Braga, 2013. Disponível em: http://repositorium.sdum.uminho.pt/handle/1822/24664.

FORMOSINHO, João. Formação de professores: aprendizagem profissional e acção docente. Porto: Porto Ed., 2009.

GUIMARÃES, Elisabete. Que relação de colaboração no contexto do estágio pedagógico? In: BIZARRO, Rosa; BRAGA, Fátima (Org.) Formação de professores de línguas estrangeiras: reflexões, estudos e experiências. Porto: Porto Ed., 2006. p.279295.

MELO, Maria do Céu. Supervisão do Ensino da História: natureza e objetos. In: BAR- 
CA, Isabel (Org.) Para uma Educação Histórica de Qualidade - JORNADAS INTERNACIONAIS DE EDUCAÇÃO HISTÓRICA, 4. Actas... Braga: Centro de Investigação em Educação, Universidade do Minho, 2004, p.87-100. Disponível em: https://repositorium.sdum.uminho.pt/handle/1822/10102.

VIEIRA, Flávia; SILVA, José Luís; VILAÇA, Teresa; PARENTE, Cristina; VIEIRA, Fátima; ALMEIDA, Maria Judite; PEREIRA, Íris; SOLÉ, Glória; VARELA, Paulo; GOMES, Alexandra; SILVA, António. O papel da investigação na prática pedagógica dos mestrados em ensino. In: CONGRESSO INTERNACIONAL GALEGO-PORTUGUÊS DE PSICOPEDAGOGIA, 12. Atas... Braga: Centro de Investigação em Educação, Universidade do Minho, 2013. p.2641-2655. Disponível em: http://repositorium.sdum.uminho.pt/handle/1822/25492.

ZEICHNER, Ken. Repensando as conexões entre a formação na universidade e as experiências de campo na formação de professores em faculdades e universidades. Educação - Revista do Centro de Educação UFSM, v.5, n.3, p.479-503, 2010.

\section{NOTAS}

${ }^{1}$ A partir do ano letivo 2015-2016, o curso oferecido pela Universidade do Minho será apenas centrado na disciplina de História. As críticas que são apresentadas neste texto foram tidas em conta na criação deste novo mestrado.

${ }^{2} \mathrm{O}$ regulamento de avaliação da UM exige que uma das suas componentes seja de carácter individual (exame oral ou escrito, teste, relatório, teste etc.).

${ }^{3}$ Ver texto de Maria do Céu de Melo neste dossiê.

${ }^{4}$ No formato de Estágio profissional anterior a este (unidisciplinar, anual), cada estagiário tinha mais do que uma turma para a sua prática pedagógica. No atual, o núcleo de estágio era composto por três ou quatro estagiários que ao longo do semestre partilhavam a mesma turma onde exerciam a sua prática didática.

${ }^{5}$ Este problema foi particularmente sentido nos estágios realizados em turmas do Ensino Secundário (que foi o meu caso) onde a pressão para uma rotina prescritiva é enorme já que a avaliação dos 3 anos que o compõem determina a entrada dos alunos nas universidades. Nos mestrados bidisciplinares como o nosso (História e Geografia) este problema foi duplamente vivido, já que o PIPS incluía em si dois estudos de caso e não apenas um.

Artigo recebido em 22 de abril de 2015. Aprovado em 28 de maio de 2015. 